\title{
SYMPOSIUM
}

\section{Sex in the city: sexual behaviour, societal change, and STDs in Saigon}

\section{L Rekart}

Sex Transm Infect 2002;78(Suppl I):i47-i54

HIV infection is increasing among sex workers and injection drug users in southern Vietnam. Vietnamese sex workers returning from Cambodia are an important factor. This phase I growth stage is being accelerated by widespread prostitution and escalating heroin use. Sexually transmitted disease (STD) rates are significant in sex workers but low in the general population. STD epidemics in developing countries may not follow the dynamic topology that is common in developed countries. Vietnam has the potential for significant HIV and STD epidemics but also the capacity to respond to these threats.

Correspondence to: Dr Michael L Rekart Director, STD/AIDS Control, 655 West 12th Avenue, Vancouver, BC V5Z 4R4, Canada: michael.rekart@ bccdc.hnet.bc.ca

Accepted 30 November 2001 l $\mathrm{n}$ this article I will provide an overview of the current social context, the political/economic situation, and the public health organisation and infrastructure in Vietnam. I will attempt to summarise information on sexually transmitted diseases (STDs), HIV infection, AIDS, and sexual networks using published and unpublished reports, data from a Canadian HIV prevention project in Ho Chi Minh City (formerly Saigon), information gathered by myself during the planning and implementation of that project, and the experiences and knowledge of reliable health care workers in Vietnam. I have attempted to verify the information presented and to state the biases and uncertainties that remain. After the contextual analysis, I will discuss the situation in Ho Chi Minh City in relation to the Wasserheit and Aral model of the dynamic topology of STD epidemics and phase specific approaches to prevention and control. ${ }^{1}$

\section{SOCIAL CONTEXT}

The Socialist Republic of Vietnam covers an area of $332000 \mathrm{~km}^{2}$ square $\mathrm{km}$ with $3444 \mathrm{~km}$ of coastline along the eastern seaboard of southeast Asia. Vietnam has borders with Cambodia $(983 \mathrm{~km})$, China $(1281 \mathrm{~km})$, and Laos $(1555 \mathrm{~km})$. It is the 13th most populous country in the world, with a population of $77236200 .^{2}$ Females represent $51.5 \%$ of the population. Vietnam's annual population growth rate is $1.5-2.0 \%$, and its population density is 219 persons $/ \mathrm{km}^{2}$. Rural inhabitants make up $77 \%$ of the population. One third of its people are under 14 years of age. The fertility rate is 3.21 babies per woman, and the infant mortality rate is $30.24 / 1000$. The death rate is $7.6 /$ 1000. The life expectancy at birth is 67 years for men and 72 years for women. The illiteracy rate is
$8.5 \%$ overall, but $71 \%$ of those who cannot read are women. ${ }^{3}$ Vietnam's per capita gross domestic product (GDP) in 1998 was \$US 352. In 1993, the World Bank estimated that $50 \%$ of the population were living in poverty and that $90 \%$ of those resided in rural areas. ${ }^{3}$ The work force is 38.2 million. The United Nations Development Program's human development ranking for Vietnam is $122 .^{2}$

Within the Association of Southeast Asian Nations (ASEAN), Vietnam has the second largest population and labour force behind Indonesia, and the fourth largest land area. Vietnam recorded the largest per cent real GDP growth for 1996 but had the lowest GDP per capita. Population growth and total fertility rate are slightly above average. Vietnam has the highest overall literacy rate $(93.7 \%)$ and one of the lowest infant mortality rates. Life expectancy is exceeded only by Brunei, Singapore, and Malaysia. Vietnam has one of the highest marriage rates in southeast Asia and one of the lowest rates of urbanisation.

The national language is Vietnamese, although English is fast becoming the favoured second language. The major religions are Buddhism, Confucianism, Taoism, and Christianity. Vietnam has more than 50 ethnic groups, but $86.8 \%$ of the population are Kinh people. There are many hill tribes of different ethnicities, which tend to be isolated and poor. Most children attend primary school and many are schooled through the secondary levels, especially in the larger towns and cities, but the dropout rate is said to be high. The Vietnamese people are increasingly mobile, with growing internal tourism and the increasing return of overseas Vietnamese who left the country near the end of the Vietnam War in 1975. Vietnam lost two to three million people during that conflict. In Vietnam, it is called the American War.

\section{POLITICAL/ECONOMIC SITUATION}

Vietnamese society is in the midst of profound social and economic change. In 1986, the Communist Party introduced the policy of Doi Moi ("renovation") which was intended to develop marketing and economic mechanisms to stimulate production, especially in the agriculture sector, and to improve overall productivity, while keeping the social and political fabric of the country intact. ${ }^{2}$ Doi Moi policies aim to increase the living standards and imbue vibrancy to the economy by encouraging private enterprise, foreign investment, production of export and import substitution goods, labour intensive projects, development of infrastructure, and foreign exchange earning services, for example tourism. This transformation was accelerated by the disintegration and the final fall of the socialist bloc and 
the socialist economic support structure in 1989. After difficulties from 1986 to 1991, Doi Moi was seen to be successful by 1995 , with inflation down to $5-10 \%$ annually and a 10 -fold increase in foreign investment. The economic growth rate in the early to mid-1990s averaged $8 \%$. In 1995, Vietnam joined ASEAN, and relations with the USA were normalised.

Vietnam communism places power within the Communist Party, and its members occupy the important government and military positions. Each geographical division is run by a People's Committee, with other committees such as Health under its control. What are called non-governmental organisations are actually under the control of the Communist Party, for instance, the Women's Union.

Vietnamese communism dictates sex equality, and several high government positions are occupied by women. However, the prime minister, the vice prime minister, and the leaders of the Communist Party and the army have always been men. Economic equality is also enshrined in the philosophy of communism, but Vietnam is not a classless society. There are upper, middle, and lower classes based on power, education, money, position, and access to information.

\section{NATURE OF SEXUAL NETWORKS \\ Commercial sex}

In Vietnam, prostitution is illegal and the government has issued several decrees to control this activity. ${ }^{4}$ Along with drug use, prostitution is considered a "social evil." Prostitution has long been viewed as a degradation of morality, a threat to public health, and a factor in the disintegration of the traditional family. It is frequently condemned in the mass media. The solution to controlling the spread of prostitution is controversial. There are three perspectives: first, prostitution is a social evil and should be eliminated owing to its negative impact on society; second, prostitution is a social phenomenon which the government cannot and should not try to control; and third, prostitution is inevitable but must be regulated and restricted to certain areas. ${ }^{3}$ Government policy largely adheres to the first perspective, but the general population is more likely to espouse the third. Police routinely crack down on prostitution, conducting "sweeps" before major holidays and events, and local authorities carry out antisocial evil campaigns which target street sex workers. Sex workers from Ho Chi Minh City who have residency permits are usually fined, but those from outside the city are often sent to re-education centres for six months of mandatory education and training. There are 40 re-education centres across the country. The fines can range from VND 200000 to 1000000 (the VND is the Vietnamese Dong; \$US $1=$ VND 14 500). The sex workers rarely have enough money to pay the fines but to avoid detention and embarrassment for their families and to continue to work, they borrow the money for the fine, usually from the owner of the bia om (pub) or cafe om (coffee bar) where they work, from the owner/manager of the apartment building where they live with other sex workers, or from loan sharks. The loans are issued at exorbitant interest rates, often 30\% a month. The sex workers repay the loans at a few thousand VND a day and consequently have little hope of ever escaping the sex trade.

At the re-education centre, the sex worker (now called a "member") is subjected to mandatory examination, testing, and treatment for sexually transmitted diseases, as well as HIV testing. Many studies are performed on this captive but biased sample, resulting in STD and HIV data that may not reflect sex workers as a whole. For instance, sex workers who have recently moved into the city from rural areas are more likely to be arrested but less likely to be infected, especially with HIV. The member is taught a trade such as embroidery or hair styling while they are educated about STDs, AIDS, and the evils of prostitution. When they are released, they receive regular visits for one year from a member of the Women's Union, but recidivism rates are as high as $80 \% .^{3}$

According to government data, there were 300000 sex workers in Vietnam in 1994, with 70000 in Ho Chi Minh City, $13 \%$ of whom were teenagers. ${ }^{24}$ There was an estimated demand for four million commercial sex acts a week in Vietnam in 1994. ${ }^{3}$ According to the Vietnam Investment Review, there were police raids involving 26711 establishments (including bars, discos, massage parlours, karaoke bars, and hair salons) in 1999. Of these, 10051 were found to be violating a government decree on the prevention of prostitution. Six hundred and seven were closed and many more received warnings.

Sex workers in Ho Chi Minh City work from many different venues. "Low income" sex workers work from the street, calling themselves "street waiters." The average charges are as follows: VND 20 000-30 000 for fondling without penetration (di xao); VND 60 000-80 000 for "quick sex" (having sex once in 30 minutes or less ) (di dau); VND 120 000-150 000 for "one hour sex" (di gio); and VND 250 000-300 000 for overnight sex. ${ }^{4}$

Younger sex workers may average two or more clients a night, while older ones do not have clients every day. Young sex workers will sometimes work from motorbikes, negotiating as they zoom along beside potential customers on motorbikes. In one central park, masturbation can be purchased for VND 5000. Street waiters are independents who pay money to their drivers for transport and for finding clients. They take clients to guest houses or to their own rented rooms, which are usually dingy and unhygienic. They consider their work to be an honest transaction. ${ }^{4}$

Younger sex workers often live together in apartment houses managed by "owners." These owners travel to rural areas and lure young girls to Ho Chi Minh City to work in cafés. When they arrive, the café jobs are non-existent and they now owe the owners for transportation to the city, accommodation, and cash advances. The owners encourage them to enter sex work and supply them with a driver.

"Middle income" sex workers work from cafe om, bia om, small restaurants, fishing clubs, hair salons, and other entertainment venues. In the pubs, the owner expects them to encourage clients to drink as much alcohol as possible. ${ }^{4}$ There are often rooms for sex on the premises which the sex worker must pay to use, usually VND 10000 . When they are arrested, the owner pays a sum of money to get them released. Compared with street waiters, they are not as often arrested, less often subjected to gang rape, and generally earn more. ${ }^{4}$ There are also women who are employed in massage parlours, where they perform body massage followed by fondling and masturbation. One particular type of stand alone bar is called a "thigh bar." Here, customers are charged by the hour to sit and talk with women while they buy drinks. Limited touching is permitted and sex can usually be arranged after hours. The total numbers, health status, and work related issues of middle income sex workers are difficult to ascertain because of the control exerted by their owners.

"High income" sex workers work in discotheques, night clubs, karaoke bars, and other high class (that is, expensive) entertainment venues. These are the most educated and attractive. There may be private rooms for karaoke singing where sex is not permitted and for which the client pays by the hour. Hotel discos usually employ women who can speak the language of the predominant hotel customer group, for example Taiwanese, Korean, or Japanese. Many high income sex workers, however, are independents who choose when, where, and with whom to have sex. They may be students, secretaries, single mothers, seamstresses, hairdressers, or professionals. They generally have few customers each week or month. High income sex trade workers may earn up to \$US 100 per sexual act. As "prostitutes" are not allowed in hotel rooms, independents take their clients to "mini-hotels" where they 
can rent a room by the hour or for the night. Some women live as "contracted wives" with foreign businessmen who have families back home.

In Phnom Penh, Cambodia, studies have shown that HIV rates among sex workers are as high as $40-50 \%{ }^{5}$ There are approximately 5000 Vietnamese sex workers in Phnom Penh, mostly from the Mekong Delta region, especially An Giang province. In a 1996 study of sex workers from a village near Phnom Penh where only Vietnamese women work (Svay Pak), the HIV infection rate was $19 \%{ }^{6}$ Most other studies of sex workers in Cambodia do not distinguish between Kinh (Vietnamese) and Khmer (Cambodian). When Vietnamese sex workers return to Vietnam, they go home first. The family situation is generally unchanged and they move to the major cities such as Ho Chi Minh City and Can Tho (the "Capital of the Mekong"), where they may resume work in the sex trade. HIV rates in sex workers increase steadily as one moves from Ho Chi Minh City to Phnom Penh. Studies have shown rates of 3\% in Ho Chi Minh City, 5\% in Can Tho, 9.5\% in An Giang, and $23 \%$ on the Cambodian side of the border. ${ }^{78}$ Inconsistent condom use, working in brothels, rural residence, and positive syphilis serology also increased, while the cost of each sex act decreased as one moved from Ho Chi Minh City to Cambodia. This geographical disease pattern of HIV infection in southern Vietnam correlates with the phase I growth stage of the dynamic topology model ${ }^{1}$; and it shows how a pathogen can be introduced at a specific location from whence it can spread to involve an entire region. This example also supports the logical notion that continuous and repeated importation of the same pathogen at the same site promotes rapid growth.

The following information was drawn from four studies published in English language journals, ${ }^{7-11}$ one research report from the Population Council ${ }^{4}$ a country visit report from the Centers for Disease Control and Prevention (CDC, Atlanta), ${ }^{12}$ and an abstract presented at International Conference on Antimicrobial Agents and Chemotherapy (ICAAC) in 1999. ${ }^{13}$ All of the information presented below was discussed with local experts.

\section{Demographics}

The average age of low and middle income sex workers was 25 to 30 years (range 15 to 51 years). Workers in cafés and bars tended to be younger. Overall, $25-50 \%$ were from outside the area where they worked, often born in nearby rural areas. Street waiters tended to be married or divorced with children. Thirty to forty per cent had attended primary school, 5-20\% had never attended school, and the rest had completed secondary school, high school, or higher. Around one quarter had other jobs. Of those with previous occupations, most were farmers, labourers, or low skill workers. Over half gave poverty or indebtedness as the primary reason why they worked in the sex trade. The debt was often incurred by other family members-for example, gambling debts of their fathers or school debts for male siblings.

\section{Sexual behaviours}

The mean duration of prostitution was 20 months, but there was a wide range-over $20 \%$ in one study had been working for one month or less. Street waiters tended to have worked longer. In one study, $89 \%$ wanted to quit. Money, a better job, and vocational training were the things most needed in order to quit. Most middle income sex workers $(74 \%)$ averaged over \$US 100 a month. In two studies, the average number of sexual partners in the last month was around 20. In one study of middle income sex worker customers, $38 \%$ were foreigners. This percentage was much smaller $(8 \%)$ in a study of 968 re-education centre members, $41 \%$ of whom were street waiters and $21 \%$ of whom worked in brothels. Brothels were more common at the Cambodian border. Around two thirds of the customers were non-regular. In the two studies which inquired about the profession of clients, $24 \%$ and $43 \%$ were traders or businessmen, $9 \%$ and $12 \%$ were office workers, $2 \%$ and $3 \%$ were seamen, and $1.1 \%$ and $0.5 \%$ were policemen or soldiers. Two thirds of the customers were 30 to 39 years old. It has been reported that a significant percentage of sex trade customers, especially in hotels, bars, karaokes, and discos, are state officials or Communist Party members. In one frank interview with a member of the Social Evils Prevention Department, it was estimated that $70 \%$ of sex work customers were members of these groups, ${ }^{3}$ making the enforcement of prostitution laws difficult.

The mean age of first sex was 19.6 years (range 12 to 25 ) in one study. However, $19 \%$ had their first sexual experience when they were less than 17 years old. Overall, 35-47\% used condoms usually or always, $26-50 \%$ sometimes, and $2-26 \%$ never. Street waiters may be arrested if they carry condoms. Some charged more for sex without a condom and most felt compelled not to use condoms to satisfy the clients. Anal and oral sex were rare; in one study, however, forced gang rape and forced anal sex were said to be common for street waiters. Physical abuse by clients was also mentioned. They were more likely to use condoms with customers than regular boyfriends or husbands; $60 \%$ to $75 \%$ never used condoms with the latter. Condoms were felt to be inexpensive. Seven per cent in one study had ever had sex during menses. Injection drug use was uncommon but alcohol was a frequent part of the sexual encounter. Around half were using some form of birth control other than condoms, usually oral contraceptives or IUDs. Many had experienced "menstrual regulation" (MR) or therapeutic abortion. In Vietnam, pregnancy termination performed within six weeks of the last menstrual period is called MR; after that, it is called abortion. Many sex workers (and Vietnamese women in general) douche or soak their genital regions regularly.

Prostitution in Vietnam has a long history. Teenage boys with time and money often purchase the services of sex workers. As in Thailand, Vietnamese men have more commercial sex with female sex workers than casual sex and may concomitantly have many sexual partners (polygamy). Some studies of Vietnamese youth and male STD clinic patients have indicated that around $20 \%$ visit sex workers and, in one study, $58 \%$ of male STD patients had their first sexual experience with a sex worker. ${ }^{14-16}$

There are areas where gay male sex workers can be found and transvestite sex workers on motorbikes are common in the main tourist area.

Non-commercial sex

Vietnam is predominantly a Buddhist country with many Confucian traditions and beliefs. The strength and unity of the family is paramount. Women are expected to be virgins when they are married, but sexual experience is desirable for men. The sexual urges of males are considered to be too strong to resist. In one survey of the general population, the percentage who had experienced premarital sex was $17 \%$ for men and $2.6 \%$ for women. ${ }^{17}$ The mean age of first sexual intercourse was 19.5 years in a 1996 study by Nhan and Hang. ${ }^{18}$

In Vietnamese society, homosexuality and bisexuality are viewed as aberrant behaviours which must be suppressed and discouraged. There are places where gay men congregate, however. The status of transsexuals and lesbians is unclear.

\section{PUBLIC HEALTH ORGANISATION AND INFRASTRUCTURE}

There are 1944 hospitals in Vietnam and 34200 doctors. ${ }^{2}$ The doctor to patient ratio is $1: 2258$. There is no national STD control or surveillance programme. ${ }^{2}$ However, in the Strategic Plan for the Prevention and Control of HIV/AIDS, strengthening the STD consultation and treatment system is stated as an important activity. The National Institute of Dermatology and 
Venereology in Hanoi has the overall responsibility for STD management and prevention. National STD syndromic treatment guidelines exist for the north and the south, differing only in that ciprofloxacin is the treatment of choice for gonorrhoea in the south, in spite of widespread ciprofloxacin resistance. ${ }^{13}$

STD patients presenting to the public system are referred to specialised STD services at hospitals or clinics which have laboratories (although some are very poorly equipped) in 53 provinces. There are five regional STD/dermatologyvenereology hospitals which provide support to the smaller centres. These are located in Ho Chi Minh City, Hanoi, Da Nang, Nha Trang, and Can Tho. Few other services in the health sector are involved in STDs. These diseases are not addressed by the extensive and well organised maternal and child health $(\mathrm{MCH})$ or family planning (FP) services although the decentralization of STD care through this system is discussed in the National Plan for HIV/AIDS. The Ho Chi Minh City and National AIDS Committees are supportive of the replication of sustainable models of STD care, outreach, and education in partnership with international donors. Treatment of STDs is implemented using a partially aetiologic, partially syndromic approach. If there is access to a laboratory test for a particular disease, this is relied upon. If not, a syndromic approach is followed. Few laboratories are able to perform microbiology testing such as gonorrhoea culture, and none routinely tests for chlamydia, although several have the proper equipment left over from previous studies conducted in association with foreign researchers. Most laboratories perform non-specific treponema testing (VDRL or RPR) but few perform specific treponema tests (TPHA or FTA-Abs). Most laboratories perform wet mounts and Gram smears. The poor utilisation of public STD services (only around 10\% of STD patients use this system) is ascribed to fear of stigmatisation, poor quality, discriminatory staff attitudes, long waits, extensive paperwork, and cost. ${ }^{212}$

In 1996, the government approved the establishment of a private health care system which has grown exponentially, but the number of private doctors and clinics and their expertise in delivering care are unknown. Most public health doctors work in both systems. In the public system, patients are charged for registration, examination, testing, and treatment. This acts as a deterrent when poor people seek care.

HIV/AIDS control is the responsibility of district committees reporting to provincial committees under the direction of the National AIDS Committee of Vietnam (NAC), chaired by the deputy prime minister. The implementing arm of the NAC is the National AIDS Bureau headed by professor A Chung, a sociologist. Hanoi and Ho Chi Minh City also have an AIDS Bureau. The NAC, the AIDS bureaus, and the 61 provincial AIDS committees have varying levels of responsibility for STD services, as no other mechanisms for STD control exist in most areas. The NAC operates by consensus among 16 Ministries, unions, and subcommittees. The level of knowledge and sensitivity to STDs and HIV/AIDS issues varies greatly among these groups. The actual front line resources (staff, supplies, facilities) are controlled by district health committees. There are 22 districts in Ho Chi Minh City. AIDS is the best funded health programme in government. The National AIDS Plan hopes to increase AIDS funding to \$US 0.3 per capita per year by 2005. Twenty five per cent of this amount will come from international donors. International agencies and NGOs spent \$US 4000000 a year on AIDS in Vietnam for the years 1997 to 1999. Government AIDS funding is allocated for medical care/ counselling $52 \%$, information/education/communications (IEC) $28 \%$, surveillance $12 \%$, and capacity building $8 \%$. Medical care/counselling funding is spent on medical equipment and testing. UNAIDS co-sponsor funding focuses on capacity building $40 \%$, STDs and blood safety $20 \%$, and injection drug use $12 \%$. International NGO funding goes to condom distribution $19 \%$ and capacity building 35\%. ${ }^{2}$ Targeted preven- tion interventions are primarily funded and delivered by international donors and UNAIDS co-sponsors, probably accounting for less than 5\% of all spending on AIDS. Local officials support some of these initiatives, even though they may conflict with official dictates. Government sponsored prevention has focused on general public education such as posters, educational events, and television.

In summary, in my view the STD control system and infrastructure within Vietnam is weak and disorganised. Good care and treatment is hard to find, especially for sex workers, injection drug users, STD patients, HIV patients, gay men, and other marginal groups.

\section{EPIDEMIOLOGY OF STDS AND HIV/AIDS \\ Sexually transmitted disease}

Around $33-50 \%$ of low and middle income sex trade workers have a history of an STD and $45-70 \%$ have a history of abnormal vaginal discharge. In one study of randomly recruited women from urban homes in northern Vietnam, 78\% said that they had an abnormal vaginal discharge even after extensive education and coaching. ${ }^{19}$ The majority of sex workers $(68-75 \%)$ self medicate for STD symptoms by purchasing drugs directly from a pharmacy, usually after advice from the pharmacist. Another 10-15\% used private doctors and 10\% public clinics. In one study, only one pharmacist's recommendation of 160 complied with official STD treatment guidelines. ${ }^{20}$ Some sex workers donate blood in the belief that the pre-donation testing will detect most STDs.

Table 1 summarises STD rates from different sources for sex workers and STD clinic patients.

Of the female population in Vietnam, 53.6\% use birth control, and $65 \%$ of these use IUDs. Only $6-7 \%$ of married couples use condoms for birth control. In one study of 1689 consecutive pregnant women presenting for prenatal care in Hanoi $(\mathrm{n}=877)$ and Ho Chi Minh City $(\mathrm{n}=812)$ in $1996,0.3 \%$ and $0.7 \%$, respectively, were found to have gonorrhoea, $2.2 \%$ and $2.5 \%$ were found to have chlamydia, and $0.2 \%$ and $0.5 \%$ had positive syphilis serology. ${ }^{3}$

\section{HIV/AIDS}

The first reported HIV infection in Vietnam was from Ho Chi Minh City in December 1990; all 61 provinces have since reported cases. As of June 2000, 20215 HIV infections were reported, including 3586 cases of AIDS of whom 1838 had died. Injection drug users account for $65 \%$ of HIV cases, female sex workers $4.8 \%$, and STD patients $2.4 \%$. Eighty six per cent of cases are male. The age group 20 to 29 years accounts for $46 \%$ of cases and 30 to 39 years for $26 \%$. Southern Vietnam, especially Ho Chi Minh City, has generated the most HIV reports $(45 \%)$. The HIV rate in Ho Chi Minh City increased from 29.2 to 41.0 per 100000 from May 1995 to December 1996. However, surveillance information is incomplete and there could be significant transmission of HIV within populations that has not yet been detected. Recent projections by the World Health Organisation and the Vietnam Ministry of Health estimate 150000 to 200000 HIV infections through the year 2000, including 50-100 000 new infections in 2000. The Ministry projects that 200000 persons will become infected with HIV from 2001 to 2005.

From 1996 to 1998, the HIV infection rate in female sex workers in Ho Chi Minh City increased from 1.2\% to $1.8 \%$, in Can Tho from $2.7 \%$ to $4.0 \%$, and in An Giang province from $3.0 \%$ to $9.5 \%$. An HIV prevalence of $4.8 \%$ was found in sex workers in Dac Lac, a border province in south central Vietnam between Cambodia and Nha Trang, a port city popular with tourists. Ten of 32 STD patients from Dac Lac were found to be HIV positive.

In Vietnam's HIV sentinel surveillance system, eight provinces from around Vietnam contribute blood samples. ${ }^{10}$ The contributing provinces included Ho Chi Minh City, Can 
Table 1 STD prevalence (\%) in sex workers and STD clinic patients from southern Vietnam *

\begin{tabular}{|c|c|c|c|c|c|c|c|c|}
\hline & GC & Syphilis & $\mathrm{CT}$ & HIV & Trichomonas & Warts & Yeast & $\mathrm{HbsA}$ \\
\hline \multicolumn{9}{|l|}{ Female sex workers } \\
\hline Reference 7 & 3 & 40 & 6 & 5.2 & 16 & 2.5 & 16 & 9 \\
\hline Reference 12 & & 16 & 19 & & 19 & & & \\
\hline Re-education $†$ & $7 / 7 / 9$ & $25 / 20 / 11$ & & & & & & \\
\hline References $9 / 10$ & & 7.1 & & 4.9 & & & & 11 \\
\hline \multicolumn{9}{|l|}{ STD clinic patients } \\
\hline $\begin{array}{l}\text { Da Lieu } \\
\text { Reference } 10\end{array}$ & 7 & 10 & & \multirow{2}{*}{1.6} & & & \multicolumn{2}{|l|}{26} \\
\hline Hy Vong§ & 5.4 & 19.2 & 14.8 & & 2.7 & 3.6 & \multicolumn{2}{|l|}{23} \\
\hline \multicolumn{9}{|c|}{$\begin{array}{l}\text { *All rates from southern Vietnam except reference } 6 \text { which presents data from eight sentinel sites throughout } \\
\text { Vietnam, of which four were in the south. } \\
\text { †At the Ho Chi Minh City re-education centre for commercial sex workers, 1994-1996. } \\
\ddagger \text { At the provincial reference centre for STDs, Da Lieu Hospital, } 1996 \text {. } \\
\S \text { Cafe Hy Vong 1999-2000. } \\
\text { CT, Chlamydia trachomatis; GC, gonococcal disease; STD, sexually transmitted disease. }\end{array}$} \\
\hline
\end{tabular}

Table 2 Results from the Vietnam sentinal surveillance system

\begin{tabular}{llllll}
\hline & \multicolumn{6}{l}{ HIV infection (\%) } \\
\cline { 2 - 6 } & 1994 & 1995 & 1996 & 1997 & 1998 \\
\hline STD patients & 0.5 & 0.4 & 0.6 & 0.9 & 1.6 \\
Sex workers & 0.6 & 1.1 & 1.3 & 2.1 & 4.9 \\
IDUs & 18.2 & 19.1 & 13.6 & 17.0 & 20.7 \\
TB patients & 0.6 & 0.7 & 0.6 & 2.3 & 2.2 \\
Pregnant women & 0.01 & 0.08 & 0.03 & 0.11 & 0.10 \\
Army recruits & 0 & 0 & 0.04 & 0.11 & 0.11 \\
\hline
\end{tabular}

IDU, injecting drug user; STD sexually transmitted disease.

Tho, and two provinces bordering Cambodia (An Giang and Kien Giang). The overall results are shown in table 2 . The predominant HIV subtype so far identified has been type E.

HIV sexual transmission among gay men undoubtedly occurs, but HIV rates are said to be less than $10 \%$ even in the major metropolitan areas.

\section{STDs and HIV in Southeast Asia}

In southeast Asia (excluding Indonesia and Myanmar), Vietnam's estimated HIV infection total in 1998 ranked third behind Thailand and Cambodia. ${ }^{21}$ It is estimated that the HIV prevalence rate $(0.2 \%)$ ranks fourth behind Thailand, Cambodia $(3.7 \%)$, and Malaysia $(0.4 \%)$. Vietnam's estimated prevalence rates in the general adult population for the $1990 \mathrm{~s}$ were $2.3 \%$ for chlamydia, $0.5 \%$ for gonorrhoea, and $0.3 \%$ for syphilis. Within ASEAN nations (excluding Myanmar, Thailand, Lao PDR, and Indonesia), Vietnam ranked behind Cambodia and the Philippines for chlamydia and gonorrhoea; and behind Cambodia, the Philippines, and Malaysia for syphilis. ${ }^{21}$

However, HIV and STD rates in Vietnam are low compared with Africa, Central and South America, the Carribean, Thailand, Cambodia, and Myanmar. One hypothesis for this difference is an older age of sexual initiation in Vietnam. Vietnamese studies of both sex workers ${ }^{9}$ and the general population ${ }^{15}$ have placed this age between 19 and 20 years. This is significantly higher than in Africa, Latin America, the Carribean, and Asia as a whole. ${ }^{22}$

\section{HO CHI MINH CITY STD/AIDS CLINIC AND OUTREACH PROGRAMME ("CAFE HY VONG")}

Cafe Hy Vong is a three year project supported by the Canadian International Development Agency (CIDA) through a partnership involving the Ho Chi Minh City AIDS Committee and the British Columbia Centre for Disease Control (BCCDC). ${ }^{23}$ The goal is to reduce the spread of HIV by treating and preventing
non-HIV STDs. The BCCDC provides training, monitoring and support. Cafe Hy Vong (hy vong translates as "hope") is the site for an STD clinic for low income sex workers and the home base for outreach peer educator teams to street sex workers and injection drug users in District 1, the main business and tourist area. Cafe Bao Cao Su 2 (bao cao su translates as "raincoat" but means condom in colloquial usage) is a similar programme in a poorer district. The clinic visit involves a complete sexual history, external and internal genital examination, on site laboratory tests, off site laboratory tests, aetiological diagnosis, treatment, education, condom distribution, and partner notification. The on site laboratory tests include syphilis testing (initially a rapid treponemal test but later an RPR), cervical Gram smear, and vaginal wet mount, Gram smear, $\mathrm{pH}$, and Whiff test. Off site tests are sent to local hospital laboratories. These include syphilis testing (initially RPR but later TPHA), gonorrhoea culture and sensitivities, and chlamydia microtrak and Pap smear. The outreach programmes focus on education, prevention, referral, condom distribution, and needle exchange. All services are free and confidential.

The training stage of the project, completed in June 1999, resulted in the training of 31 Vietnamese health care workers and the production of a training package in both Vietnamese and English, including manuals for clinic, laboratory, administrative, and outreach staff. There are videos in both languages showing male and female genital examinations, proper wound care for injection drug users, and vein maintenance, as well as flow charts, algorithms, and pocket manuals with pictures of anatomy and STDs. Much of the training package has been transferred to CD-ROM.

The training stage was judged successful based on the following evaluative tools ${ }^{23}$ :

- Improved scores on a knowledge quiz

- Daily feedback from participants

- Week 1 evaluation workshop

- Continuing education workshop on the last day

- Final programme evaluation form

- Workshop facilitators critiqued presentations along with outside observers

- Feedback from the trainers

- Post-training monitoring: feedback from patients and staff, review of clinic records, audits, and ongoing monitoring activities.

The most important factors in the success of the training stage were felt to include political commitment, personal and professional relationships, the adaptability of the trainees, the skill and experience of the trainers, regular contact between the partners, written contracts, combined training, direct 
Table 3 Official sexually transmitted disease case reports in Vietnam

\begin{tabular}{lllllllll}
\hline Year & 1991 & 1992 & 1993 & 1994 & 1995 & 1996 & 1997 & 1998 \\
\hline Syphilis & 3363 & 4012 & 6123 & 5820 & 3903 & 3064 & 3194 & 3088 \\
Gonorrhoea & 7368 & 5226 & 12852 & 9706 & 6678 & 4882 & 6586 & 6859 \\
Other STDs* & 10298 & 10488 & 35428 & 33686 & 33557 & 37915 & 62010 & 109241 \\
\hline
\end{tabular}

transfers of money and materials, translating all materials into Vietnamese, and flexibility in delivery.

\section{Ongoing challenges}

The project is currently in the programme stage: to establish high quality, user-friendly free and confidential clinic and outreach services. Several challenges have arisen.

Societal attitude toward sex workers and injection drug users is the most difficult underlying issue. Vietnamese society considers sex workers and injection drug users to be evil, and this view is supported by the government's social evils campaign which seeks to identify, arrest, re-educate, and eliminate these aspects. This extends to the health care system in which it is difficult to find committed workers, especially doctors, for these populations. For example, the Cafe Hy Vong doctor position was occupied by four different physicians in the first two years of the project. Initially the clinic was often "cancelled for the day." I did not feel the sense of urgency that pervades so many STD and HIV/AIDS programmes in Canada, the USA, and elsewhere.

The police are also a problem. Poorly paid and trained, the police hassle injection drug users, sex trade workers, and even peer educators. When detained "prostitutes" are given fines, these are not recorded and receipts are not given, making it easy to deny or ignore this repressive practice. Some street waiters owe more than VND 5000000 and many can never hope to leave sex work. This makes education, prevention, and behaviour change difficult.

\section{Lessons learned}

\section{Condoms and needles}

When the project began, the six sex worker peer educators distributed about 100 condoms in total each week and no needles. The IDU peer educators gave clients one needle each day and no condoms. They worked separately. Currently, both teams distribute as many condoms and needles as necessary to supply client needs, several hundred every week. The IDU and the sex worker teams also meet regularly and sometimes work together. This collaboration is important because, on the one hand, a growing number of sex workers are smoking and injecting heroin and, on the other hand, more young, sexually active people are using drugs. Cafe Hy Vong became Vietnam's first fixed needle exchange site in early 2000 .

\section{Drug use, sex work, and HIV}

As heroin has become more available, young people have begun to smoke heroin and, when money runs low, they switch to injection. The IDU re-education centre membership is now primarily young heroin users rather than the older opium injectors. Poor and uneducated young people, some 13 to 14 years old, move to Ho Chi Minh City from rural areas and participate both in sex work and injection drug use. Young women inject drugs by day and work in the sex trade by night. Some sleep in the streets and commit petty crimes to raise money. Over half of newly admitted sex workers at the Ho Chi Minh City re-education centre injected drugs in 2000. Results from HIV testing in these centres over the 18 months ending in June 2000 have shown a dramatic rise in HIV infection. Sex worker rates have risen from $2.3 \%$ to $21.6 \%$ and IDU rates from $18.6 \%$ to $62.9 \%$. Sex workers who have worked in Cambodia had an HIV infection rate of $88.4 \%$.

\section{Reliance on laboratory results}

The health care staff rely heavily on laboratory results to make a diagnosis. This has caused problems with the diagnosis of yeast vaginitis, cervicitis, and bacterial vaginosis. Bacterial vaginosis tends to be diagnosed and treated whenever the vaginal smear is positive by Nugent criteria, despite guidelines that take into account the presence of an abnormal discharge, symptoms, $\mathrm{pH}$, and the Whiff test. When patients return after being treated once for bacterial vaginosis, they are often wrongly classified as a treatment failure and retreated entirely on the basis of laboratory results.

\section{Talking to patients}

Talking with patients about their history and symptoms, especially their sexual history and their genital symptoms, is uncommon in Vietnam. There is a clear demarcation between the doctor who does the examination and makes the diagnosis, the nurse who records demographic information on patients and gives the treatments (particularly the injections), and the patients.

\section{Intramuscular penicillin}

The staff at both cafes are hesitant to give intramuscular injections of penicillin. They have little confidence in their ability to handle anaphylactic reactions and no faith in the local emergency response system. They will seize any opportunity to avoid intramuscular penicillin, even a history of food allergies.

\section{Administration}

One of the most challenging areas has been administration. Inventory, purchase orders, planning ahead, retaining receipts, drafting small contracts, generating reports, petty cash funds, and accurate administrative records are new concepts.

\section{Syndromic management}

The WHO guidelines on the syndromic management of STDs have been of great assistance in resource-poor settings, but the vaginal discharge algorithm can present difficulties in countries like Vietnam where there is confusion about what kind and how much vaginal discharge is abnormal.

\section{Other issues}

The widespread use of syndromic management in areas where there are trained health care workers who can do internal genital examinations and laboratories that can perform diagnostic tests is an issue. Various combinations of syndromic and aetiological management are often instituted, based not on the capability of the local health care system but on expediency and cost. When syndromes rather than diseases are diagnosed, the local epidemiology of specific STDs is lost. When genital ulcer disease, for example, is the syndrome diagnosed, and both chancroid and syphilis are treated, neither the prevalence nor the incidence of either disease is known. And what of herpes? In addition, algorithmic problems are difficult to recognise. If the syndrome of vaginal discharge is overdiagnosed and overtreated but this goes 
unrecognised, there will be excess cost and unnecessary drug reactions. In rural and resource-poor settings, training health assistants to perform pelvic examinations and setting up diagnostic laboratories may not be practical but, in the major cities like Ho Chi Minh City and Manila, the reliance on syndromic guidelines undervalues local health care workers and results in missed opportunities to build capacity. One can see the limitations by examining the official 1991-1998 STD rates for Vietnam (table 3). Of 119188 total reported STDs, over $90 \%$ were syndromic diagnoses for which aetiologies can only be guessed. UNAIDS will conduct an evaluation of the Cafe Hy Vong project.

\section{DISCUSSION}

Vietnam is changing and many of these changes will make HIV and STD transmission easier. People are increasingly mobile; premarital sex is more common; economic development and information dissemination are growing; the gap between the rich and the poor is widening; sex work and injection drug use are increasing rapidly; and more sex workers are drug users and vice versa. HIV and STD rates are generally low compared with many parts of the world but HIV rates are increasing in certain populations. The HIV epidemic in Vietnam is clearly in a phase I growth pattern. ${ }^{1}$ The rapidity with which it reaches a phase II hyperendemic level will be determined not by the pathogen itself but by population dynamics and prevention efforts.

On the population dynamics side, sexual networks will be the critical factor. The current spread networks are contained within subpopulations at the lowest levels of education, income, power, and prestige. While this may give the leaders of the country hope that HIV will be limited, however tragically, to a small segment of society, this is false solace in a country where societal change is itself in a rapid growth phase. An important population dynamic is poverty. The mix of pre-existing poverty and rapid economic development can, in the short term, result in more rather than fewer have-nots. When large numbers of people move in and out of poverty on a regular basis, one wonders whether that group can become a spread network capable of carrying a pathogen between rungs of society. When one is poor, survival is paramount. Doing the right thing about sex, drugs, disease, and risk takes a back seat.

On the prevention efforts side, social networks are crucial. Social networks are said to be more open than sexual networks, marked by higher rates of interchange and linkages across population subgroups and greater numbers of social contacts. ${ }^{1}$ Social networks characterised by higher education, income, power, prestige, and good health care will naturally have greater access to prevention information and will be more responsive to prevention messages. The normal diffusion of information, attitudes, beliefs, life styles, and behaviour patterns between subpopulations can be inhibited, however, in a poor country that is changing so rapidly that gaps between subpopulations are widening. Where money and material goods are scarce, access to information itself becomes an important commodity. Too often the most up to date medical textbooks sit forlorn and untouched in the bookcases of hospital directors.

\section{Dynamic topology of STDs in Vietnam}

The natural and controlled history of STD epidemics, as elucidated by Wasserheit and Aral, ${ }^{1}$ describes a disease pattern beginning with a growth phase during which technical experts recognise the issue and initiate research; this is followed by a hyperendemic phase during which opinion leaders designate resources for detection, intervention, and prevention; there is then a decline phase when the reproductive rate falls below 1; and finally an endemic phase occurs, during which the population, the pathogen, and prevention reach equilibrium. The HIV epidemic in Vietnam presents an uncontrolled pattern in which one disease (HIV) is growing rapidly and is recognised by the technical experts, requiring no new research to detect or to prevent. But adequate priority and resources have not been designated for its control. Some STDs in Vietnam, such as gonorrhoea and chlamydia, are probably in the growth or hyperendemic phases within certain populations. Adequate research has not been initiated by the technical experts to document this, nor have adequate priority or resources been designated, even less so than for HIV. Adequate information does not exist to even guess at whether any STD, for instance syphilis or chancroid, has entered a decline or endemic phase. Information on herpes does not exist at all.

Do STD epidemics occur in controlled and predictable patterns in developing countries? The first time an STD breaks out in a developed country, it may follow the natural and controlled pattern. Once that has occurred, however, the rapid spread of information, pathogens, populations, and technology around the globe make it unlikely that a controlled, phase specific pattern will occur again, especially in poor nations.

The Vietnam HIV example clearly shows what can happen in developing countries. The world recognised AIDS in 1982, and HIV a few years later, with an accurate diagnostic test available in 1985. The routes of transmission for HIV and most of the important and effective prevention strategies have been known for at least 15 years. Soon after AIDS was first diagnosed in Vietnam in 1990, the Ministry of Health, working closely with WHO and the Global Programme on AIDS (GPA), developed estimates and projections for HIV spread and a medium term plan to combat this disease. All along, Vietnam has had Thailand as a regional example of how rapidly HIV can spread and how effective simple prevention measures can be. What has happened? HIV remains, 10 years later, in a phase I pattern of disease growth with detection methods inaccessible to patients, with opinion leaders either avoiding the issue or blaming the victims, with cheap and effective prevention initiatives available only inconsistently (condoms) or not at all (needles), and with a paucity of designated resources. What is missing? Why has not HIV in Vietnam assumed its rightful place on the phase specific curve and followed the well marked path to phase II, III, and IV, like a good little germ?

The answer may be that the totally logical evolution through predictable phases for STD epidemics depends on more than the pathogen, the population, and the prevention efforts. Certainly other factors like money, culture, and religion can drive or block efforts to control HIV/AIDS and STDs. But are these just surrogate markers for something else?

Money and resources can be helpful when a country decides to track a disease and to prevent it. Research moves faster as well. But there are simple and inexpensive tools for doing good research, for detecting infections, for surveillance, and for prevention. Community surveys, sentinel surveillance, urethral/ cervical Gram stains and cultures, syndromic management, patient histories, condoms, and needles do not require vast sums of money.

Culture and religion are often blamed for inaction and neglect, especially in relation to marginal groups such as sex workers, drug users, homosexuals, the mentally challenged, and ethnic minorities. Benign neglect is a convenient argument when resources are scarce. And who is easier to exclude than the poor and the uneducated, in other words the powerless. But are religion, culture, and society the real culprits? What culture teaches us to blame young girls who sell their bodies and their honour to pay gambling debts for their fathers, schooling for their brothers, or hospital bills for their mothers? What religion teaches us that the sick and disadvantaged deserve our scorn rather than our sympathy?

The real issue is human rights. Ensuring basic human rights allows STD epidemics to evolve through a controlled and predictable pattern, eventually coming into some semblance of 
control. The absence of basic human rights turns this pattern on its head. The presence or absence of basic human rights dictates the timing, the scope, and the effectiveness of a society's response to STDs, new or old. If there has been a single, most important lesson learned in the Cafe Hy Vong project thus far, it has been the paramount importance of attitudes. Negative attitudes toward individuals and groups at risk interfere with every initiative to control and prevent HIV and STDs. Conversely, positive attitudes support and enhance every initiative. And positive attitudes are resource-neutral. It costs no money for governments to proclaim that sex workers are equal members of society or, at least, not to be blamed. It costs no money for the media to report the daily struggles of drug users and how much like the rest of us they really are. It costs nothing for hospitals and doctors to treat poor people with respect. No one is harmed except, of course, the drug dealer, the pimp, the brothel owner, the paedophile, and those who derive riches and power by denying human rights.

\section{Conclusions}

Vietnam is at a crossroad. The country is stable and developing. The people are hard working and thirsty for knowledge. The society and culture are strong. Yet the potential for a devastating epidemic of HIV/AIDS and STDs is real. Vietnam is one of only a few countries in the developing world that does not yet have a large per capita HIV/AIDS/STD epidemic but does possess the ability to prevent one. Many epidemics can be viewed as preventable but, in this case, the tools are at hand and the people are ready. Vietnam could be one of the world's greatest HIV/AIDS/STD success stories or one of history's saddest examples of lost opportunity. Jonathan Mann was correct: human rights are the key. ${ }^{24}$

\section{ACKNOWLEDGEMENTS}

We thank Dorothy Rachar, Elsie Wong, Linda Knowles, Laura MooreDempsey, Juanita Maginley, Ingrid Pocock, Jacqueline Barnett, Norah Young, Daphne Spencer, David Patrick, Ron Zapp, Chung A, Le Truong Giang, Truong Xuan Lieu, Le Thuy Lan Thao, Jamie Uhrig, Robert Brunham, Canadian International Development Agency (CIDA), Joe Knockaert, Stephen Kraus, Daniel Tarantola, Jonathan Mann, the project staff in Vietnam and all of our patients.

\section{REFERENCES}

1 Wasserheit JN, Aral SO. The dynamic topology of sexually transmitted disease epidemics: Implications for prevention strategies. J Infect Dis 1996;174(suppl 2):S201-3

2 Chung A, ed, for National AIDS Committee of Vietnam. Vietnam's National HIV/AIDS programme. Hanoi, Vietnam, 2000.

3 CARE Vietnam. An overview of the situation in regard to HIV/AIDS in the Socialist Republic of Vietnam. Hanoi, Vietnam, 1997.

4 Population Council Vietnam. Access to reproductive health services of sex workers in Ho Chi Minh City. Research report No 7. Hanoi, Vietnam, 1999.
5 World Health Organisation. The epidemic in the Western Pacific Region: current status and future trends. STD/HIV/AIDS surveillance report (WHO No 8), November 1996, Manila, 1996.

6 Ryan CA, Vathiny OV, Gorbach PM, et al. Explosive spread of HIV-1 and sexually transmitted diseases in Cambodia. Lancet 1998;351:1175.

7 Thuy NTT, Nhung VT, Thuc NV, et al. HIV infection and risk factors among female sex workers in southern Vietnam. AIDS 1998;12:425-32.

8 CARE Cambodia. The border areas HIV/AIDS prevention project. Technical paper SR1. Phnom Penh, Cambodia, 2000.

9 Thuy NTT, Lindan CP, Hoan NX, et al. Sexual risk behavior of women in entertainment services, Vietnam. AIDS Behav 2000;4:93-101.

10 Hien NT, Long HT, Chi PK, et al. HIV monitoring in Vietnam: system, methodology, and results of sentinel surveillance. J Acquir Immune Defic Syndr 1999:21:338-46.

11 Giang LT, Son NT, Thao LTL, et al. Evaluation of STD/HIV prevention needs of low- and middle-income female sex workers in Ho Chi Minh City, Vietnam. AIDS Behav 2000;4:83-91.

12 Gayle H. Foreign trip report - Vietnam, January 1997. Atlanta Georgia: US Centers for Disease Control and Prevention, 1997.

13 Tien P, Giang LT, Thuc NV, et al. Prevalence of non-ulcerative sexually transmitted disease among high risk women in HCMC, Vietnam using simultaneous culture and non-culture testing. ICAAC, 26-30 September 1999, San Francisco [abstract 1740].

14 Thuy NTT, Hau TP, Thuong NV, et al. Developing a method of HIV/AIDS estimation and projection using transmission models in $\mathrm{Ho} C h i$ Minh City. In: Scientific research abstracts on HIV/AIDS in Vietnam, June 2000. Hanoi: National AIDS Committee of Vietnam, 2000.

15 Thuy NTT, Lindan CP, Phong TH, et al. Predictors of visits to commercial sex workers by male attendees at sexually transmitted disease clinics in southern Vietnam. In: Scientific research abstracts on HIV/AIDS in Vietnam, June 2000. Hanoi: National AIDS Committee of Vietnam, 2000.

16 Dung NXA, Le DT, Tri LD, et al. HIV/AIDS and young people; a KABP study in Ho Chi Minh City. In: Scientific research abstracts on HIV/ AIDS in Vietnam, June 2000. Hanoi: National AIDS Committee of Vietnam, 2000.

17 Goodkind D, Anh PT, Vinh DX, et al. Study of knowledge, attitudes, and practices related to HIV/AIDS spread among the young adults in Hanoi by different methods. In: Annals of scientific studies on HIV/AIDS. Hanoi: National AIDS Committee of Vietnam, 1997.

18 Nhan VQ, Hang NDM. Reproductive behavior of unmarried urban students of age 17-24 in Viet Nam. In: Reports of the National Seminar on Social Research Relevant for HIV/AIDS. Hanoi: National AIDS Committee of Vietnam, 1996.

19 Go V, Quan VM, Zenilman J, et al. Treatment-seeking behavior and barriers to care among women with RTI symptoms in North Vietnam. XIII International Conference on AIDS, Durban, 9-14 July 2000. [[Abstract MoOrD151]]

20 Uhrig J, Hung ND. Availability and quality of STD care in four provinces of Vietnam. Prepared for the National AIDS Committee and Family Health International Vietnam by the Vietnam Institute of Dermato-Venereology, Ho Chi Minh City, Vietnam, 1998

21 The Western Pacific Regional Office of the World Health Organisation. Status and trends of STI, HIV and AIDS at the end of the millennium, Western Pacific Region, 1999. Geneva: WHO, 1999.

22 Aggleton P, Rivers K. Interventions for adolescents. In: Gibney L, DiClemente RJ, Vermund SH, eds. Preventing HIV in developing countries: biomedical and behavioral approaches. New York: Plenum Press, 1998:231-55

23 Rekart ML. The Ho Chi Minh City STD/AIDS Clinic and Outreach Program. Results of the training phase. Vancouver: British Columbia Centre for Disease Control (BCCDC), 1999.

24 Aral SO, Mann JM. Commercial sex work and STD: the need for policy interventions to change societal patterns. Sex Transm Dis 1998;25:455-6. 